\title{
Erratum to: An effective salvage treatment using ifosfamide, etoposide, cytarabine, dexamethasone, and rituximab (R-IVAD) for patients with relapsed or refractory aggressive B-cell lymphoma
}

Katsuhiro Miura $\cdot$ Kazuhiro Takei $\cdot$ Sumiko Kobayashi $\cdot$ Satomi Kiso $\cdot$ Yukio Hirabayashi $\cdot$ Atsuko Hojo Hitomi Kodaira $\cdot$ Mai Yagi $\cdot$ Daisuke Kurita $\cdot$ Yujin Kobayashi $\cdot$ Toshitake Tanaka Noriyoshi Iriyama Yoshihiro Hatta $\cdot$ Yoshimasa Kura · Tetsuo Yamazaki $\cdot$ Umihiko Sawada · Jin Takeuchi

Published online: 14 July 2011

(C) The Japanese Society of Hematology 2011

Erratum to: Int J Hematol (2011) 94:90-96

DOI 10.1007/s12185-011-0884-x

An error appeared in the original version of this article, unfortunately. On the second page, in Sect. 2.2, "Treatment," on line 10 it is stated that dexamethasone was administered on days 1-3; however, the administration period should be correctly stated as days $3-5$.

The online version of the original article can be found under doi:10.1007/s12185-011-0884-x.

K. Miura $(\bowtie) \cdot$ K. Takei · S. Kobayashi · S. Kiso ·

Y. Hirabayashi - A. Hojo $\cdot$ H. Kodaira - M. Yagi · D. Kurita

Y. Kobayashi - T. Tanaka · N. Iriyama · Y. Hatta · Y. Kura ·

T. Yamazaki · U. Sawada · J. Takeuchi

Division of Medicine, Department of Hematology

and Rheumatology, Nihon University School of Medicine,

30-1 Oyaguchikamicho, Itabashi Ward, Tokyo, Japan

e-mail: javis@med.nihon-u.ac.jp 